\title{
SOBRE MÉTOdOS PARA PESQUISA DE CONCEITOS ${ }^{1}$
}

Leonid Sakharov

Tradução de Gisele Toassa; revisão técnica de Achilles Delari Júnior

RESUMO [DA TRADUTORA]

O presente texto corresponde à comunicação realizada em 1 de janeiro de 1928 em uma Conferência Pedológica de Moscou, focando particularmente os procedimentos metodológicos relativos à pesquisa ontogenética do desenvolvimento de conceitos. Nas duas primeiras partes, Sakharov elabora crítica aos métodos para pesquisa de conceitos, focando os das definições e os de abstração. Na terceira, o autor analisa o método de busca de Narziss Ach, considerando-o como fonte primária da aplicação do método funcional da dupla estimulação ao estudo da formação de conceitos, elaborado por Sakharov sob a liderança de L.S. Vigotski e apresentado na quarta parte. Acrescenta-se tradução das notas explicativas de René van der Veer. O texto é um clássico da psicologia histórico-cultural, sendo publicado pela primeira vez em língua portuguesa a partir de tradução do inglês, cotejada com o russo.

Palavras-chave: método funcional da dupla estimulação; formação de conceitos; método de Sakharov; psicologia histórico-cultural; Leonid Solomonovich Sakharov (1900-1928).

\section{ON METHODS FOR INVESTIGATING CONCEPTS}

\section{Abstract}

This text corresponds to a talk made by Sakharov on 1 January 1928 in a Pedological Congress in Moscow, focusing particularly on the methodological procedures of ontogenetic development of concepts. In the first two parts, Sakharov criticizes methods for researching concepts, focusing on the definitions and abstraction methods. In the third, the author analyzes a search method by Narziss Ach, considering it as a source of application of functional method of double stimulation to study the formation of concepts, drawn by the author under the leadership of LS Vygotsky and presented into fourth part. Notes published in English translation by René van der Veer are also translated. The text is a classic of cultural-historical psychology, published for the first time in Portuguese in a translation from the English, compared with a Russian version.

Keywords: functional method of double stimulation, concept formation, method of Sakharov, cultural-historical psychology, Sakharov, Leonid Solomonovich (1900-1928).

1 Dicionários consultados: EUdict :: Russian-English Dictionary (disponível em http://www. eudict.com/); VOINOVA, N., STARETS, S., VERKHUCHA, V., \& ZDITOVETSKI, A. (1989) Dicionário russo-português. Moscou: Russki Yazik; o Google Tradutor e o Portal de Dicionários Iandex (disponível em http://slovari.yandex.ru/). 


\section{Método das definições e SEU SIGNIFICADo PARA PESQUISA de CONCEITOS}

\section{INFANTIS}

Um dos problemas que têm contribuído para um refinamento do "método funcional de estimulação dupla" (funktsionalsnaya metodika dvoinoi stimulyatsii) em experimentos é o problema da formação de conceitos em crianças. Para formar uma ideia da significância desse método experimental para o estudo de conceitos infantis, este deve ser concebido no contexto de outros métodos que têm sido utilizados para lidar com o mesmo problema. A psicologia dos conceitos infantis não só é de tremendo interesse teórico, mas também indubitavelmente tem significado psicológico aplicado desde que a acumulação de conceitos, sua natureza e o modo como são utilizados são inquestionavelmente correlacionados ao nível de desenvolvimento intelectual da criança e tornam-se, em alguma medida, indicadores daquele nível. Portanto, não é surpreendente que testes sobre conceitos ocupem um lugar de honra entre os sistemas de testes existentes, e que seu valor diagnóstico tem ganhado amplo reconhecimento.

O método das definições (metod opredeleniya) é o mais conhecido dentre os vários métodos para estudo dos conceitos infantis. Também tem-se colocado em muitos diferentes sistemas de testes para medir talento intelectual (umstvennoi odarennosti). As técnicas seguintes para estudar conceitos infantis são modificações do método de definição: o experimentador enumera atributos que são parte do conteúdo de um conceito e pede à criança para nomear o conceito ou conceitos, ou a criança deve produzir um conceito genérico unindo todos os atributos. Tanto no primeiro como no segundo caso, o método indutivo é escolhido - de atributos (priznak) aos objetos, de espécie a gênero. Entretanto, o método dedutivo também é utilizado: um conceito genérico é dado, e se requer da criança que nomeie as espécies que são parte dele; à criança é oferecido um conceito genérico e um atributo identificatório (differentia specifica) e se pergunta quais diferenças existem entre espécies do mesmo gênero, ou entre gênero e espécie. Todos esses procedimentos complementam o método de definição. Uma vez que eles fazem menos exigências à criança, são usados com mais sucesso que a definição direta em alguns casos - quando, por exemplo, uma criança tem dificuldades óbvias de expressão verbal.

O método de definição tem sido usado não apenas como teste para medir talento intelectual (caso de Binet, Bobertag e outros autores de versões de uma escala métrica, como Gregor, Roloff etc.), mas também em estudos experimentais devotados particularmente a conceitos infantis (Pelsma, Eng). Qual lugar o método de definição e todas as técnicas similares a ele ocupam entre métodos para estudar conceitos infantis? Eles são, por assim dizer, métodos indiretos para estudar conceitos (Moede). ${ }^{(1)}$

Métodos indiretos focam o acervo de conceitos que uma criança possui. A natureza deste acervo é estudada. O propósito da investigação não é o processo de gênese dos novos conceitos na criança, mas as características qualitativas de conceitos já existentes. Mas de modo algum até essas características qualitativas têm sido estudadas exaustivamente - talvez nem mesmo seus aspectos mais im- 
portantes. O método de definição não pode nos dizer como a criança usa conceitos na resolução de diferentes tarefas vitais. De fato, um índice das características qualitativas de um conceito é, no caso particular, não o uso prático desse conceito pela criança em suas respostas aos objetos no mundo ao redor dela, mas a descrição verbal do conteúdo ou do escopo do conceito. Nós obtemos essa descrição sob condições experimentais ou de teste. Entretanto, esse índice não é apenas incompleto: não é nem mesmo claro.

A mesma definição de um conceito pode ter significado fundamentalmente diferente para duas crianças diferentes. Em um caso, pode ser uma reprodução mecânica de uma fórmula que foi decorada, mas não trabalhada. A criança simplesmente repete de memória o que tem ouvido. Em outro caso, a definição pode ser o resultado da atividade real e trabalho perseverante, lógico. Isto é porque os psicólogos alemães falam sobre Scheinbegriffe e echte Begriffe (quase conceitos e conceitos genuínos). Recomendações variadas têm sido dadas sobre como combater a ambiguidade dos resultados do método de definição. Assim, tem sido dito que as questões não deveriam presumir qualquer conhecimento específico, por memorização mecânica do que está escrito nos livros.

Entretanto, todos sabem o quão difícil é evitar esse ponto. Um aspecto diferencial da natureza ativa da atividade de definição tem posteriormente sido apontado: a consternação e confusão da criança depois de receber a tarefa. Entretanto, até se houvesse possibilidade de encontrar um critério relevante que seria suficientemente objetivo e prático, as dificuldades não terminariam aí. Posteriormente, os resultados do trabalho lógico são comunicados por meio da linguagem. A fórmula para definição consiste de uma série de palavras que deveria permanecer para conceitos particulares. Nós sabemos que uma criança aprende uma linguagem, ela absorve uma multidão de palavras, mas o conteúdo dessas palavras ela usualmente aprende de forma extremamente imperfeita, rudimentar. Ora, o significado de uma palavra algumas vezes permanece oculto para ela, ou ao menos de algum modo indeterminado. Tudo isso é, certamente, capaz meramente de intensificar a ambiguidade de resultados experimentais.

O que faz uma criança arranjar certas palavras, do que é feita a definição de um conceito? Esta questão ainda permanece aberta. Por exemplo, Lindworsky considerou necessário para o experimentador trabalhar individualmente com cada criança e determinar por meio de questões especiais, como ela entende as palavras usadas para definir o conceito. "Testes massificados são de pouca ajuda", diz Lindworsky, "se o significado e o valor de cada caso individual não for estabelecido". (2) Porém, nos estudos de massa que têm sido realizados por meio do método de definição, [a injunção de Lindworsky - G.T.] não tem sido cumprida.

\section{ESTUDO EXPERIMENTAL DOS PROCESSOS DE ABSTRAÇÃO EM CRIANÇAS}

As principais imperfeições no método de definição são: ele falha completamente em tomar em consideração os processos de geração de conceitos e trabalha somente com conceitos terminados; até estes últimos são utilizados em termos de apenas um aspecto, e não o mais importante deles; e os estudos são 
realizados sob condições que deixam dúvidas sobre a natureza inequívoca dos resultados obtidos. A razão para essas fraquezas está nas condições de qualquer experimento com algum método de definição.

Os estímulos excitatórios do comportamento de uma criança em um experimento $^{2}$ são palavras que expressam conceitos correspondentes, isto é, eles representam grupos definidos de atributos, comuns a diferentes objetos e abstraídos deles. Estes objetos não servem como estímulos no experimento. A reação da criança é novamente limitada à "representação vocal" dos atributos correspondentes. Mas o escopo da resposta generalizada aos estímulos no mundo ao redor, e, especialmente, o problema da gênese dessa resposta estão no centro do interesse psicológico na aprendizagem de conceitos, particularmente dos infantis. ${ }^{(3)}$ Como, de reações condicionadas a situações determinadas (que sejam similares entre si em vários sinais), produzem-se típicas reações conceituais; quais dentre elas desempenham o papel de fatores; quais processos psicofisiológicos têm lugar aí? Finalmente, se uma resposta similar a um conceito já foi elaborada, quais são suas características na ação? Essas são questões de importância cardeal que quase nunca são mencionadas pelo método das definições. Portanto, o segundo grupo de métodos é de muito maior interesse, isto é, métodos para investigar conceitos e estudar diretamente processos subjacentes à formação de conceitos.

Em primeiro lugar, há métodos experimentais para pesquisar processos de abstração em crianças. Uma vez que nossa comunicação refere-se apenas a métodos de investigação, devemos omitir qualquer coisa que tenha a ver com a definição de abstrações, com teorias existentes nessa questão etc. Em experimentos sobre abstração, apresenta-se ao sujeito um conjunto de impressões, seja simultânea ou sucessivamente. Alguns elementos desse conjunto são repetidos. $O$ sujeito seleciona do número total de impressões aqueles elementos que são similares, seja com ou sem instruções, e os abstrai afirmativamente (polojitelno). A velocidade e acurácia em seguir as instruções servem como indicadores do nível de desenvolvimento dos processos de abstração no sujeito. Experimentos que estudam processos de abstração recaem em dois grupos, dependendo de quais impressões gerais recorrentes devem ser afirmativamente abstraídas pelo sujeito. Em um caso, eles podem ser objetos comparativamente independentes; em outro, atributos independentes comuns a um número de objetos, por exemplo, cor e forma. Exemplos de estudos desse tipo são os realizados por Koch, Habrich e Von Kuenberg, com crianças normais, e por Heffler, com surdas-mudas. Esses quatro autores introduziram na psicologia infantil um método para investigar abstração que foi usado pela primeira vez com adultos por Grünbaum. ${ }^{(4)}$ Em suas características gerais, o método consiste no seguinte: a criança é apresentada a um grupo de figuras sem significado, separado por uma linha em dois grupos; uma luz de projeção ou projetor de slides é utilizado. No caso mais fácil, cada subgrupo contém duas figuras; há também dois subgrupos de três, quatro, cinco ou seis figuras cada. Uma figura é repetida em ambos os subgrupos; todas as outras são diferentes. $\mathrm{O}$ tempo de apresentação é de três segundos. A tarefa da criança é encontrar a figura idêntica nos dois subgrupos, apontando, em uma banda (lente) vazia, o lugar que é ocupado, e

2 Literalmente: excitantes, estimuladores do comportamento da criança em um experimento (N. da T.). 
então procurá-la em uma ficha de controle, entre 20-25 figuras. Esses experimentos mostraram que a capacidade para abstração aumenta com a idade, e é correlata à inteligência (odarennost). Acima de tudo, quanto mais difícil é a tarefa, isto é, maior o número de figuras em um grupo, maior é a influência da superioridade das crianças intelectualmente talentosas (odarennix detei).

Eliasberg, em um estudo de psicologia e patologia da abstração, oferece sérias críticas do método de Koch, Habrich e von Kuenberg. ${ }^{(5)}$ Ele aponta que esses experimentos requerem das crianças, em adição ao processo de abstração, finalização de um número de operações de ordem secundária, por exemplo: procura de duas figuras similares, memorização delas, reconhecimento delas em uma série de muitas outras, localizando-as em um lugar específico de uma folha de papel etc. A realização bem ou mal-sucedida dessas operações tem uma influência essencial no resultado do experimento, e então os resultados obtidos não são suficientemente indicativos do processo de abstração. Heffler, por outro lado, provou que, nesses experimentos, crianças com um tipo visual de imaginação tiveram uma vantagem considerável e, no fim, fizeram melhor que crianças intelectualmente talentosas (odarennikh) que tinham outro tipo de imaginação. Do ponto de vista do estudo do processo de formação de conceitos em crianças, a maior inadequação desse método está em outra parte. Entretanto, essa inadequação também é inerente a outros métodos de estudar abstração em crianças. Portanto, vamos mergulhar brevemente neles.

Um exemplo de experimentos com abstração de atributos independentes de objetos, cores, formas etc., ao invés de objetos comparativamente independentes (por exemplo, figuras individuais), são os de Katz. ${ }^{(6)}$ Katz mostrou uma figura geométrica simples a crianças pré-escolares, por exemplo, um triângulo vermelho, e selecionou dentre um grupo de figuras dispostas em uma mesa, uma figura exatamente igual ao modelo. A tarefa não pôde, claramente, ser realizada, pois entre as figuras na mesa havia algumas similares ao modelo na forma, mas eram de cores diferentes, enquanto outras eram idênticas em cor, mas diferentes na forma. Katz ajustou seu experimento para verificar se crianças pré-escolares poderiam abstrair afirmativamente, isto é, para determinar se poderia surgir uma resposta positiva estável para qualquer atributo em combinação com outros. As instruções nos experimentos de Katz requeriam que a criança respondesse à total similaridade. Entretanto, essa resposta era impossível nas condições experimentais. O que uma criança faria? Ela atuaria de forma completamente aleatória, ou mostraria uma resposta constante a um atributo específico? A qual, cor ou forma? Assim, a característica principal do método de Katz era que se requeria da própria criança selecionar o critério de abstração, se ela era, afinal, capaz de abstrair. Descobriu-se que, na maioria das instâncias, as crianças escolhiam figuras da mesma cor do modelo. Por exemplo, se o experimentador mostrasse um triângulo vermelho e houvesse três círculos vermelhos e três triângulos na mesa, as crianças quase invariavelmente iriam escolher os círculos. Katz concluiu que crianças pré-escolares tinham a capacidade de singularizar um atributo específico comum a certo número 
de objetos e reagir a ele (e que a cor impactava mais do que a forma em crianças entre as idades de dois anos e nove meses e cinco anos). Em experimentos nos quais cores competitivas eram eliminadas, as crianças abstraíam a forma.

Os experimentos de Katz suscitaram dúvidas, então Tobie testou o método dele em 1924 em um estudo amplo, envolvendo cerca de mil crianças. ${ }^{(7)}$ Tobie estabeleceu três fases no desenvolvimento infantil. A primeira, até três anos e oito meses, é caracterizada pelo fato de que uma orientação para cor ou forma depende da saliência (Aufdringlichkeit) de um ou outro desses atributos na situação em particular, não em condições gerais. Isto é o que ele chama de zona de sugestibilidade (Zone der Suggestibilität). Então se segue uma zona de cor (de três anos e nove meses a cinco anos), quando a criança é orientada para a cor em virtude de fatores constitucionais. Nos últimos meses dessa zona, a criança transita para uma orientação à forma. $\mathrm{Na}$ idade de cinco anos e dois meses, começa uma nova zona em que domina a orientação à forma; mas, depois, a capacidade de abstrair afirmativamente_em ambas as direções aparece.

Podemos mencionar outro tipo de método para estudar processos de abstração em crianças. É o método de Eliasberg, que o usou principalmente em experimentos com crianças pré-escolares, que podem ser descritos como se segue. Folhas de fino papelão cortadas em 4 X $10 \mathrm{~cm}$, de diferentes cores (verde, vermelho, azul e amarelo), são preparadas. Essas folhas (listki) são dobradas em arco e pequenas tiras (papiroski) de papel são coladas na metade interna; para serem vistas, elas têm de ser viradas. Folhas de duas cores são usadas em cada experimento. As folhas de uma cor têm as tiras colocadas; as de outra, não. Por exemplo, cinco folhas amarelas têm tiras e cinco azuis não, as quais são dispostas aleatoriamente na mesa.

O experimentador dá à criança duas folhas extras: amarela com uma tira, azul sem ela, e pede-lhe para virá-las. Então, retira-as da criança e as esconde. Agora o experimentador aponta para as folhas sobre a mesa e diz: "Agora olhe lá". A criança começa a brincar com as folhas, virando-as e rearranjando-as de um lugar para outro, enunciando seus pensamentos e perguntando. Finalmente, ela indica que não há nada mais para fazer. Se há algumas crianças que desde o início não sabem o que devem fazer e não mostram sinal de atividade, o experimentador lhes dá ciência de que deveriam pôr à parte as folhas com as tiras de papel. Então a criança é posta de lado, e durante esse tempo, algumas das folhas de papel ou todas elas são trocadas por outras. Por exemplo, as folhas azuis sem as tiras são substituídas por folhas de uma nova cor, também sem tiras. A cor positiva permanece a mesma (amarela), e a cor negativa (azul) é trocada por uma nova. Em outro caso, a cor positiva é modificada. Em um terceiro caso, revertem-se as cores positivas e negativas; e em um quarto caso, um par de cores é completamente substituído por outro, etc. Uma das modificações mais interessantes é uma ou duas folhas de cor positiva serem substituídas por uma ou duas folhas da mesma cor, mas sem as tiras. Este experimento é denominado Storungsversuch (disruptivo), pois viola a lei ligando dois atributos (a cor e a presença das tiras). Quando uma das mudanças é feita, a criança é novamente levada à mesa e se dá liberdade para que brinque com as folhas. $\mathrm{O}$ experimentador grava todas as suas 
ações e palavras tal como ela faz. Então, faz-se novamente uma pausa, uma modificação etc. Assim, vemos que nos experimentos de Eliasberg o comportamento do sujeito não tem nada a ver com a realização de uma tarefa específica. Eliasberg estuda os processos naturais e espontâneos de abstração em crianças (aufgabefreie naturliche Beachtungsvorgange). A única instrução que a criança recebe do experimentador ou de toda a situação é procurar as folhas com as tiras. Eliasberg está interessado em quão rápido e de que modo a criança chega ao entendimento da conexão entre a cor das folhas e a presença ou ausência de tiras sobre elas. Todas as modificações feitas no material durante o experimento servem para desenvolver na criança um puro entendimento abstrato dessa conexão, a saber: que "de duas cores, só uma tem o atributo considerado (tira)".

Eliasberg aponta que, em todos os estudos precedentes sobre abstração em crianças, a abstração provou ser demasiado próxima e limitada pela natureza sensorial do material. A abstração não transcende os limites do concreto. $\mathrm{Na}$ análise final, Koch, Habrich, von Kuenburg e Katz requereram da criança que ela percebesse relações de similaridade entre atributos concretos de objetos indiferenciados em termos de contexto sensorial. Os estudos de Eliasberg, pela primeira vez, puseram a questão de se processos de abstração que levavam ao desenvolvimento de reações comuns generalizadas não apenas para estímulos conhecidos, mutuamente similares, levavam também para relação totalmente formal entre quaisquer estímulos, a despeito de sua natureza sensorial, no comportamento natural de crianças pré-escolares.

Temos examinado os métodos básicos para estudar processos de abstração em crianças. Qualquer pessoa que se aproxime desses métodos do ponto de vista do problema da formação de conceitos não pode evitar perceber uma propriedade comum (obcheie svoistvo) a todos: que processos de abstração são estudados em situações essencialmente estranhas a condições naturais em que esses mesmos processos levam à formação de conceitos. Na formação de conceitos [natural], a abstração é dirigida e guiada por palavras. Os produtos de abstração, portanto, entram em uma relação íntima com as palavras, e um conceito nasce: o significado de uma palavra. Mas os procedimentos de Koch, Habrich, von Kuenberg, Katz e Eliasberg diferem naqueles processos de abstração estudados em uma situação que exclui levar em conta o papel funcional das palavras, fator mais importante na formação de conceitos.

Realmente, em todos esses experimentos, o papel das palavras, como fator que organiza e guia os processos de abstração, é reduzido a um mínimo. No método de Eliasberg, as palavras nem mesmo determinam o objetivo último para o qual a criança deveria esforçar-se, pois, em geral, não há tais objetivos nesses experimentos. Uma das principais conclusões de Katz é que, a despeito de se dar à criança a tarefa de encontrar figuras idênticas aos modelos, ou vice-versa, isto é, figuras completamente diferentes, ela se comportará exatamente do mesmo modo e escolherá figuras similares em cor. Assim, a despeito do assim dito insuficiente desenvolvimento da compreensão de fala (riétch) pela criança, as instruções, por assim dizer, apenas mobilizaram processos, sem determinar sua direção ou estágios individuais. $\mathrm{O}$ comportamento da criança é estimulado exclusivamente 
por uma série de estímulos-objeto (predmetnix razdrajitelei). Estímulos verbais são completamente ausentes ou, ao menos, não têm influência direta nas relações da criança para com os estímulos-objetos. No experimento de Koch, Habrich e Von Kuenburg, a direção da abstração é determinada pelas instruções, especificamente: procurar figuras similares; mas isso é precisamente determinado como em qualquer experimento no qual se dá uma tarefa ao sujeito por meio de instruções. Por meio de palavras, o sujeito recebe a tarefa real de abstrair de um dado conjunto de elementos similares; mas tão logo começa a executar essa tarefa, suas ações são determinadas exclusivamente pelo mundo objetivo com o qual ele está lidando. Divergências quanto a essa lógica servem como indicadores da defectividade e insucesso das operações psicológicas. Palavras não guiam as operações psicológicas; portanto, o produto obtido não forma um conceito. Não apenas mencionamos o fato de que o método de Grünbaum, usado pelos três autores, baseia-se em abstração de elementos comparativamente independentes de um conjunto, não atributos dependentes comuns a um número de objetos. Isso também o priva de qualquer valor para o estudo dos processos de formação de conceitos, pois o conteúdo deste último é apenas uma combinação de atributos dependentes.

Assim, ao passo que o método de definição não vai mais longe que as palavras participantes no processo de formação de conceitos, o método para pesquisa de abstrações limita-se exclusivamente a objetos com base nos quais um conceito é formado, sem levar em consideração que um conceito nasce somente se as operações psicológicas da criança, dirigidas para objetos, são guiadas por palavras, isto é, se a criança usa palavras como meio para guiar o processo de abstração em uma ou outra direção. "Palavras sem material sensorial, ou material sensorial sem palavras": o que, ao fim e ao cabo, é o contraste entre o método de definição e o de estudo de abstrações.

O mais interessante é que todos os estudos de processos de abstração em crianças, enumerados anteriormente contrariam o fato de que o nível de desenvolvimento dos processos de abstração e o papel da fala no comportamento infantil dependem da extensão dos recursos verbais delas. Dados sobre o trajeto desenvolvimental dos processos de abstração em relação com a idade para crianças normais e surdas-mudas são interessantes a esse respeito (Habrich, Heffler). Em crianças ouvintes, o processo é especialmente intensivo durante a primeira metade do período escolar, e consideravelmente mais lento na segunda metade. Para surdos-mudos, o contrário é o caso: primeiro, surdos-mudos atrasam consideravelmente, em relação a crianças normais, mas depois avançam de modo significativo. De acordo com os dados de Linder, o atraso de crianças surdas-mudas em processos de abstração combinado com uma clara superioridade sobre crianças normais em termos de reconhecimento de pessoas; e, com respeito a lembrar figuras sem sentido, eles meramente atrasam-se com relação a crianças normais. O mesmo é verdadeiro na sua memória de Schriftbilder ${ }^{(8)}$ Por outro lado, em cada caso em que o processamento de dados da experiência sensorial (tchuvstvennovo opita), singularizando o que é essencial, percebendo e utilizando relações, ou abstraindo, é tarefa a mais do que a simples memorização, a criança surda-muda está bem atrás de seu par normal de mesma idade. Isso parece claramente ser uma 
questão de desenvolvimento retardado das funções correspondentes por causa da surdez e falta de fala, como evidenciado pelo fato de que, ao redor do terceiro ou quarto ano de escolarização, quando crianças surdas-mudas aprendem a falar, a capacidade de abstração delas começa a aumentar de forma aguda, e a diferença entre elas e as crianças normais diminui consideravelmente. Como diz Heffler, "uma revolução intelectual tem lugar em uma criança surda que aprende a falar em uma escola para surdos-mudos; esta revolução é similar à que tem lugar em crianças ouvintes de três a seis anos de vida. Em ambos os casos, a descoberta do significado da língua (znatcheniya yazika) e de sua função de nomeação é a fonte de uma mudança fundamental no comportamento infantil. Questões espontâneas sobre os nomes dos objetos e os propósitos e causas das coisas e processos são provas de que, neste ponto, a criança pequena, ouvinte, e a escolar surda-muda começam a realizar diferenciações e ordenar na diversidade infinita ao redor delas; elas começam a reconhecer relações e sistemas de relações, e assim crescem dentro do mundo de conceitos do ser humano adulto". Dados interessantes sobre o papel da linguagem no processo de abstração são providenciados por Descoeudres e Beckmann. ${ }^{(9)}$ Esses autores observaram que crianças normais entre as idades de seis e oito anos acharam muito mais fácil imaginar um número correspondente de objetos com base em um numeral que lhes foi dado, do que nomear o número de objetos apresentados a elas. Isso significa que "um símbolo verbal abstrato, usado repetidamente e de muitos modos", promove o processo de abstração de infinitos conjuntos de objetos de contagem ao conceito de número. "A língua impulsiona nosso pensamento ao longo do caminho da abstração", diz Lindner. Nós encontramos dados similares em Eliasberg. No estudo discutido anteriormente, Eliasberg demonstrou diferentes resultados dependendo de qual dos três tipos o sujeito pertencia. O primeiro grupo consistia de crianças com bom desenvolvimento geral e da fala. O segundo grupo compunha-se de crianças de desenvolvimento normal que eram um pouco atrasadas na fala. $\mathrm{O}$ terceiro grupo de crianças compunha-se daquelas que eram pobre e fracamente desenvolvidas em geral e muito atrasadas na fala. Foi observado que as crianças do segundo grupo, aquelas que tinham se desenvolvido normalmente, mas eram retardadas na fala, tinham mais dificuldade, que as crianças do primeiro grupo em abstrair da experiência sensorial, e eram mais ligadas a situações sensoriais concretas.

Assim, o papel educacionalmente estimulante das palavras em processos de abstração está fora de dúvida. $\mathrm{O}$ estudo de processos de abstração tal como eles têm lugar sob o norteamento direto das palavras, sendo, portanto, o mais interessante. Os métodos experimentais analisados acima, entretanto, não nos permitem estudá-los.

\section{MÉTOdos de ESTUdo EXPERIMENTAL dO PROCESSO DE FORMAÇão DE} CONCEITOS EM CRIANÇAS

Nós delineamos em linhas gerais o ambiente imediato em que o método da estimulação dupla (metod dvoinoi stimulyatsii) nasceu e foi gradualmente desenvolvendo-se para uso no estudo de conceitos infantis. Uma breve história esquemática desse tema reduz-se, grosso modo, ao seguinte. Nós temos encon- 
trado as fontes disso na velha psicologia experimental. Em 1912, um estudo feito pelo psicólogo subjetivista inglês Aveling foi publicado, sob o título "On the consciousness of the Universal and the Individual". O próprio autor chamou seu trabalho de "contribuição à fenomenologia dos processos de pensamento". E, de fato, seu propósito foi estudar, de uma perspectiva fenomenológica, processos de pensamento. "O que é passível de descoberta em nossa consciência (soznanie) quando pensamos sobre o geral ou o individual, quando nós pensamos 'homem'? E 'este homem' ou 'todos os homens'?”, pergunta o autor. ${ }^{(10)}$ A questão foi colocada de modo similar na psicologia empírica longo tempo antes de Aveling. Um dos primeiros foi Ribot, com seu "Questionário sobre ideias gerais". ${ }^{11)}$ Antes de Aveling, psicólogos da Escola de Würzburg, usando o método da autoobservação, tentaram realizar uma caracterização fenomenológica dos processos de pensamento e, em particular, os processos de experiência subjetiva do significado das palavras, julgamentos, inferências etc. Contudo, Aveling fez uma mudança substancial no método experimental. Ele propôs estudar a vivência de conceitos (perejivaniya ponyatii) associados não com palavras da língua materna, mas com palavras artificiais criadas experimentalmente. Aveling mostrou a seus sujeitos séries de figuras. Cada série continha cinco figuras retratando alguns objetos que eram similares entre si, por exemplo, cinco frutas diferentes, cinco flores diferentes, cinco diferentes instrumentos musicais, cinco pássaros de diferentes espécies etc. Uma palavra sem sentido estava sob cada figura, a mesma para todas as figuras em cada série. Por exemplo, todas as flores tinham a inscrição "Kumic"; todos os pássaros, "Tuben”; e todas as frutas, "Digep". Em um período superior a vários dias, os sujeitos aprenderam o significado das palavras sem sentido e criaram associações entre essas palavras e as figuras correspondentes a elas. Isso foi feito como se segue. Foram apresentadas aos sujeitos, em ordem aleatória, figuras de séries diferentes. Eles tiveram que ler em voz alta as palavras sem sentido e olhar para a figura correspondente atentamente por 10-15 segundos. Na segunda metade de cada sessão, depois de uma pausa de dez minutos, o experimentador nomearia as palavras sem sentido que os sujeitos vinham estudando e começaria a sessão de treino. O sujeito tinha de ouvir a lista atentamente e responder com a palavra "sim" tão logo o significado da palavra experimental que ele lesse aparecesse em sua consciência. Então, o sujeito daria uma descrição detalhada das suas experiências, baseadas na autoobservação. Depois de 20 sessões, depois das associações entre as palavras sem sentido e os objetos correspondentes terem sido mais ou menos firmemente fixadas, Aveling realizou experimentos envolvendo a "Complementação de Partes de Julgamentos". Aveling diria algumas sentenças incompletas em que as palavras experimentais eram os sujeitos_(gramaticais - G.T.) e o sujeito (experimental - G.T.) tinha que lhe atribuir um adjetivo apropriado. As palavras experimentais tinham agora um significado individual e, então, um geral. Por exemplo, o experimentador começaria como se segue: "Todos os Digep são...", e o sujeito teria de terminar a sentença. Ou: "Nenhum Kumic é...", "A primeira Sorab é...". Depois de completar a sentença, os sujeitos comunicariam o que eles tinham notado na autoobservação. Os velhos estudos sobre o problema da vivência do sentido das palavras, feitos por psicólogos da escola empirista, usavam o mesmo método. O que foi único no procedimento de 
Aveling? O experimentador apresentaria ao sujeito uma palavra-estímulo, e o sujeito tinha que responder a ela com alguma outra palavra, ou não responder a ela, e então, mediante um dado sinal, descrever experiências eliciadas pela palavra-estímulo. Aveling permaneceu completamente nos limites da introspecção.

O que o fez decidir não usar as palavras da língua materna como estímulos? Exclusivamente interesses de introspecção. Ele esperou, desse modo, evitar as dificuldades constantemente encontradas na auto-observação. Essas eram dificuldades em distinguir as vivências de sentido de uma palavra (perejivaniya smisla slova) das próprias vivências associadas à percepção da própria palavra como estímulo auditivo ou visual. Nós somos incapazes de ouvir qualquer palavra de nossa língua materna sem que seu significado surja em nossas cabeças, tão intimamente eles se relacionam. Aveling quis, de algum modo, diminuir a velocidade desse processo de transição da vivência da forma verbal para vivência do sentido da palavra, e então introduziu novas palavras que não eram tão estreitamente fundidas com os conceitos correspondentes. Portanto, está bastante claro que Aveling não estudou o processo de formação de conceitos, mas somente processos de vivência do que já tinha sido completado, dos conceitos que os sujeitos já possuíam, por exemplo, os conceitos de fruta, instrumento musical etc.

Entretanto, a inclusão no experimento (junto com as figuras dos objetos), de palavras relacionadas a esses objetos e o uso de palavras experimentais especiais, foi parte do procedimento de Aveling que tinha futuro no estudo dos processos de formação de conceitos - é claro, com a rejeição da posição puramente fenomenológica, subjetiva, de Aveling. Um estudo de Ach, o fundador da escola Determinationspsychologie, marcou um avanço decisivo. Seu estudo foi publicado no livro "Über die Begriffsbildung", que veio à luz em 1921. ${ }^{(12)}$ Ach conduziu experimentos não só com adultos, mas também com crianças. Seu método de estudar conceitos, o assim chamado método de busca (Suchmethode), foi baseado nos seguintes postulados teóricos, a formulação dos quais foi, sem dúvida, um dos méritos de Ach.

1. Não é possível se limitar ao estudo de conceitos já prontos; o processo de formação de novos conceitos é importante;

2. O método de investigação experimental deveria ser sintético-genético; durante o curso do experimento, o sujeito deve gradualmente chegar à construção de um novo conceito - portanto, há a necessidade de criar conceitos experimentais com o agrupamento artificial de atributos que pertencem a eles;

3. É necessário estudar o processo pelo qual as palavras adquirem significado, o processo de transformação de uma palavra em um símbolo e uma representação de um objeto ou de um grupo de objetos similares - portanto, há a necessidade de usar palavras experimentais artificiais que são inicialmente sem sentido para o sujeito, mas adquirem sentido durante o curso do experimento; 
4. Conceitos não podem ser considerados como estruturas fechadas, autossuficientes, e não podem ser abstraídos da função a que servem na sequência de processos mentais. Os processos de condições objetivas, ou seja, um conjunto de objetos possuidores de propriedades comuns, não é suficiente para a formação de conceitos. Um ser humano não pode ser visualizado como um filme fotográfico passivo, no qual recaem as imagens dos objetos reforçando-se entre si em suas partes similares e formando um conceito, como a fotografia coletiva de Galton. A formação de conceitos também tem precondições subjetivas e requer a presença de uma necessidade (psicológica) definida, que é a função do conceito satisfazer. No pensamento e ação, o desenvolvimento de um conceito desempenha o papel de instrumento para alcançar certos fins. Este aspecto funcional deve ser levado em conta em um procedimento investigatório; um conceito deve ser estudado em seu contexto funcional. Nós devemos perseguir o caminho tomado por Köhler, que em seu estudo da inteligência de antropoides colocá-los-ia em situações a serem resolvidas somente pela utilização de certas ferramentas, de modo que o uso funcional daquelas ferramentas se tornasse um indicador do nível do comportamento intelectual do animal. ${ }^{(13)}$ Similarmente, em um experimento, o sujeito deve ser confrontado com tarefas que podem ser realizadas somente se o sujeito desenvolve certos conceitos. O desenvolvimento desses conceitos vai requerer o uso de séries de signos verbais sem sentido para solucionar o problema, e como resultado esses signos vão adquirir um sentido específico para o sujeito.

Esses são os postulados principais nos quais Ach baseou seu método de busca (Suchmethode). ${ }^{(14)}$ Vamos agora caminhar em uma descrição concreta do procedimento como foi utilizado com crianças.

O material experimental foi uma coleção de figuras geométricas feitas de papel cartão ${ }^{3}, 12$ de cada cor: vermelhos, azuis, amarelos e verdes (48 ao todo). Cada conjunto de 12 figuras foi separado por tamanho, peso e forma. Seis figuras de cada cor eram grandes e seis, pequenas. Os seis itens grandes foram divididos por forma em dois cubos, duas pirâmides e dois cilindros, os pares sendo externamente idênticos. Um cubo, pirâmide e cilindro foram preenchidos, e eram pesados, enquanto seu par era leve. A mesma divisão foi feita para as seis pequenas unidades de cada cor: dois cubos, duas pirâmides e dois cilindros, um de cada forma pesado e o outro, leve. Assim, as unidades de cada cor consistiam de três pesados e largos, três leves e largos, três pequenos e pesados e três itens pequenos e leves.

Vemos que a coleção de figuras era estritamente simétrica. Os experimentos foram realizados em três fases. A primeira foi um período de prática (eine Übungsperiode); a segunda, um período de busca (Suchperiode); e a terceira, um período de teste (Prüfungsperiode). Cada sessão começou com um período

3 Kartona - papel cartão ou cartolina (N. da T.). 
de instrução. As figuras foram arranjadas na frente da criança. Pedaços de papel com as palavras escritas foram nelas pregados. Todas as figuras grandes e pesadas receberam etiquetas com a palavra "gazun"; os objetos grandes e leves receberam etiquetas com a palavra "ras"; os objetos pequenos e pesados, a palavra "taro"; e os pequenos e leves, a palavra "fal". Primeiro, os sujeitos tinham que lidar com apenas um pequeno número de figuras Então, a cada nova sessão, o número de figuras aumentava, até chegar a 48 . No primeiro dia dos experimentos, as crianças começaram com apenas seis grandes figuras azuis. Elas foram arranjadas de uma maneira padronizada. As figuras pesadas com o rótulo "gazun" foram dispostas mais perto de um sujeito em uma primeira fila. Para a esquerda estava um cubo, seguido por uma pirâmide e, finalmente, um cilindro. As figuras leves com a inscrição "ras" foram adicionadas em uma segunda fila. Estas foram arranjadas na mesma ordem de modo que o cubo leve ficou atrás do pesado, etc. As figuras na segunda fila não pareciam diferentes, para o olho, das figuras na frente deles. Para determinar as diferenças, elas tinham que ser viradas.

$\mathrm{O}$ experimentador deu à criança a instrução de erguer suavemente a figura e dizer em voz alta o que estava escrito nela. Inicialmente, ele ergueu o cubo grande e pesado do lado esquerdo do sujeito, e então o cubo leve atrás dele, a pirâmide pesada, seguida pela leve etc. Esse procedimento foi, usualmente, repetido três vezes. Então a criança foi virada, enquanto os pares de figuras foram rearranjados: uma figura pesada de qualquer forma, junto de suas inscrições, foi mudada para a segunda fila no lugar do objeto leve, e o último foi colocado na primeira fila onde ficara o pesado. Como resultado, a ordem normal (normale Ordnung) foi realocada por uma ordem trocada (vertauschte Ordnung). A criança novamente ergueu as figuras na mesma sequência e leu o que estava escrito nelas.

Depois de três ensaios, as figuras foram novamente rearranjadas. Agora elas estavam sem qualquer padrão espacial, em completa desordem (a assim-chamada bunte Ordnung). Três novos exercícios foram realizados, então se fez uma pausa de quatro minutos, durante a qual o experimentador removeu as inscrições das figuras, escondeu-as e mudou as figuras em uma nova ordem sem qualquer padrão, como antes. O período de prática, que consistia de uma normal, trocada e aleatória, terminou, e um período de busca (Suchperiode) começou. A criança recebeu as instruções: "Encontre e separe todas as figuras nas quais um pedaço de papel com a palavra "gazun" foi escrita uma vez. Você deve pegá-las." Quando essa tarefa foi completada, fosse como fosse, perguntou-se à criança porque ela pensou que "gazun" tinha sido escrita nas figuras postas de lado. O tempo decorrido até a conclusão da tarefa, a ordem de disposição das figuras e a explicação dada pela criança foram gravadas. Se a tarefa fosse realizada incorretamente, o experimentador dizia: "Você errou", sem indicar qual fora o erro.

A primeira tarefa foi seguida por uma segunda, terceira e quarta. A criança tinha que dizer o que permanecia e o que estava escrito nas figuras remanescentes. Se ela trabalhasse incorreta ou hesitantemente, o período de prática era repetido, depois de uma pausa de cinco minutos, com as mesmas figuras, e a criança tinha que resolver os mesmos problemas. 
A criança então se moveu para a prática e realizou as tarefas com as seis figuras pequenas, "taro" e "fal". Tudo foi feito na mesma ordem. No fim dessa sessão, ou na próxima sessão do dia seguinte, 12 figuras azuis arranjadas em ordem normal foram imediatamente apresentadas para o sujeito, as grandes para a esquerda, e as pequenas para a direita. Depois de três sessões práticas, as figuras foram rearranjadas em ordem alterada, e então, aleatória. No período de busca a criança tinha que realizar não duas, mas quatro tarefas, que eram: selecionar figuras nas quais a palavra "gazun", "taro" e "ras" tinham sido escritas e dizer quais permaneciam. Nas sessões seguintes, o sujeito foi apresentado a 24, 36 e 48 figuras imediatamente depois de uma prática preliminar e tinha de realizar as mesmas tarefas. A solução de cada uma requereu a apresentação de seis figuras além de três quando elas eram figuras de três cores, e 12 quando figuras de quatro cores foram apresentadas. De fato, quando havia 48 figuras na mesa, eram 12 "gazuns" grandes e pesados, três azuis, vermelhos e verdes e três amarelos.

Depois de cinco a sete sessões, uma criança normal, na maioria dos casos, terá dominado completamente as tarefas requeridas dela, abstrairá da cor e forma das figuras, e começará a justificar sua escolha dos mesmos dois atributos das figuras que são parte dos conceitos, a saber: peso e tamanho. O tempo gasto em realizar a tarefa torna-se consideravelmente mais curto, e, ao selecionar a figura necessária, a criança deixa de agir aleatoriamente e não faz movimentos supérfluos. Em um grau ou outro, ela começa a seguir uma certa ordem (Ordnungsizlpien), baseada, por exemplo, no princípio da cor ou forma, isto é, no que é útil para ela, primeiro entre as figuras de uma cor, então entre figuras de outra etc.; ou também ela começa com cubos, então seleciona das pirâmides e finalmente dentre os cilindros. A contagem é usada para checar a perfeição da conclusão da tarefa (se tudo tiver sido selecionado). Depois de se familiarizar com a estrutura da coleção, a criança é agora capaz de resolver a tarefa pelo raciocínio. Assim, por exemplo, se as figuras leves e grandes são "ras" e já tiverem sido selecionadas, então quando a criança recebe a tarefa de selecionar figuras "gazun", ele pode por à parte todas as grandes figuras remanescentes sem pesagem, pois na coleção há apenas dois tipos de figuras grandes, e se "ras" já tiver sido selecionada, somente "gazun" permanece. É claro que nem todas as crianças são igualmente capazes de desenvolver tais técnicas auxiliares para trabalhar com conceitos. Há diferentes níveis de talento intelectual (stepeni odarennosti), e uma ampla faixa etária também. Finalmente, o experimento entra em sua última fase, a fase de testes. Este período é necessário para estabelecer se as palavras previamente sem sentido: "gazun", "ras", "taro" e "fal" adquiriram algum sentido para a criança devido à sua utilização funcional (Prüfungsperiode). O experimentador propõe um certo número de questões: "Como 'gazun' difere de 'ras'?" "São [as] 'gazun' maiores do que "taro"?" "São 'taro' mais pesadas ou leves que "fal'?". "O que é 'ras'?", "O que é 'taro'?" etc. A criança responde as questões sem olhar as figuras, e suas respostas e tempo requerido para respondê-las são gravadas. Então, começa um experimento maselonovskiano de formação de frases. ${ }^{(15)}$ Por exemplo, solicita-se a uma criança compilar uma frase na qual as palavras "ras" e "gazun" aparecem. Isso termina os experimentos. 
Assim, vemos que, durante o período de testes Ach usou um método de definição e técnicas similares a este com respeito à formação de novos conceitos. Isso requer tanto a definição de novos conceitos quanto indicação de diferenças entre eles. Se agora nós examinarmos cuidadosamente o curso global dos experimentos do início ao fim, não é difícil ver que os experimentos atravessam dois estágios em termos do número de atributos a ser afirmativamente abstraídos e associados às palavras experimentais. O primeiro estágio (Stufe der Grundeigenschaft) envolve trabalho com apenas seis figuras azuis - primeiro, com as grandes, então com as pequenas. Nesse estágio, a palavra experimental induz o sujeito a fazer uma abstração positiva de apenas um atributo, o peso. Para ser capaz de selecionar figuras "gazun" ou "ras" dentre as grandes, a criança deve saber que "gazun" é escrita nas figuras pesadas. Para resolver as mesmas tarefas com as figuras pequenas, a criança deve novamente levar em consideração somente o fato de que "taro" está escrita nos rótulos dos objetos pesados e "fal", nos leves. Quando a criança tem 12 figuras diretamente diante de si, os experimentos entram no segundo estágio, o estágio de diferenciação primária. A combinação de dois pares de signos "gazun" e "ras", e "taro" e "fal" em uma série verbal impele o sujeito a fazer uma abstração positiva de um atributo a mais, o tamanho. Para completar a tarefa, o sujeito agora tem que associar dois atributos, peso e tamanho, com cada palavra experimental: "gazun" são grandes e pesadas, "taro" são pequenas e pesadas etc. Isso começa o conteúdo final dos conceitos experimentais. Entretanto, depois que a primeira série de experimentos terminava, Ach usualmente fazia uma segunda série usando o mesmo procedimento, como continuação do primeiro. A única diferença com relação ao primeiro era que o conceito incluía um atributo a mais, cor, e depois, também um quarto atributo, forma. Em lugar dos quatro conceitos "gazun", "ras", "taro" e "fal", haveria agora 16: "bu-gazun" (grande, pesado, azul), "ge-gazun" (grande, pesado, amarelo), "ro-gazun" (grande, pesado, vermelho) e "nu-gazun" (grande, pesado, verde); então "bu-ras" (grande, leve, azul), "ge-ras" (grande, leve, amarelo), etc. Seguindo o mesmo princípio, em vez de apenas "taro", nós temos agora "bu-taro", "ge-taro", "ro-taro" e "nu-taro"; e no lugar de "fal", temos "bu-fal", "ge-fal", "ro-fal" e "nu-fal". Mantendo a mesma série de objetos, mas enriquecendo e diferenciando a série de signos, Ach observou um novo aspecto do processo de abstração tanto quanto novos conceitos.

O autor denomina esse estágio do experimento de estágio da diferenciação secundária. A diferenciação primária teve lugar na primeira série, quando o atributo do tamanho foi adicionado ao peso. Os experimentos foram completados com um terceiro estágio de diferenciação quando cada um dos 16 conceitos elaborados no estágio precedente foi diferenciado em três novos conceitos com respeito ao atributo "forma". As palavras experimentais não eram mais "bu-gazun", "ro-gazun", etc., mais "bu-gazun-I" (o que significa cubo grande, pesado e azul), "bu-gazun-II" (pirâmide grande, pesada, azul), "bu-gazun-III" (cilindro grande, pesado, azul), "ro-gazun I", "ro-gazun-II", "ro-gazun-III", etc. Cada conceito agora continha o atributo de tamanho, peso, cor e forma, e já que na coleção de figuras de Ach não havia duas figuras com a mesma combinação desses quatro 
atributos, o produto do terceiro estágio de diferenciação foram 48 conceitos individuais. O conteúdo de um conceito aumentou de estágio para estágio, mas o âmbito diminuiu constantemente, até alcançar unidade.

Assim foi o procedimento de Ach. Ele, brevemente, descreveu-o assim:

O sujeito recebe tarefas que não pode completar sem a ajuda de alguns signos inicialmente sem sentido... Essas tarefas podem ser realizadas corretamente apenas com base na observação prévia e atenta das palavras e atributos (escritas nos rótulos) de objetos atribuídos a tais palavras... Os signos (palavras) são meios pelos quais o sujeito pode realizar um fim específico, o de resolver os problemas colocados pelo experimentador; e por causa de lhes ser atribuído tal uso, adquirem um significado inequívoco. Eles começam a ser veículos de conceitos para o sujeito. O sujeito pode usar esses signos, agora repletos de significado, para tecer declarações sobre o estado de coisas, e essas declarações serão entendidas pelo experimentador (12, p.33).

Talvez devesse se enfatizar, em conexão com essa descrição, que a analogia que naturalmente se sugere entre as palavras experimentais de Ach e as sem sentido de Ebbinghaus para o estudo da memória está correta em apenas um aspecto: em ambos os casos a razão para utilizar as sílabas ou palavras sem sentido foi o desejo de atingir resultados inequívocos em experimentos e trabalhar com material que deveria ser independente da experiência passada individual do sujeito. Entretanto, tudo o mais parece totalmente diferente. As sílabas sem sentido para estudo da memória continuaram a permanecer sem vida, sem sentido durante o curso dos experimentos. Mas nos experimentos de Ach (graças à influência de Köhler em seu método), a falta de sentido das palavras desempenha o papel de algo que deve ser eliminado; o desenho do experimento, e todos os esforços do sujeito, são dirigidos contra ele, e o processo experimental é, ao mesmo tempo, de transformação de um sinal sem significado e o de transformar signo sem sentido em uma palavra significativa.

Ach programa seus experimentos quase que exclusivamente para adultos. Para testar a aplicabilidade de seu Suchmethode a crianças, ele também incluiu quatro crianças de cinco, seis, sete e oito anos. As de cinco e seis não sabiam ler, e então pegariam as figuras e repetiriam as palavras corretas após o experimentador. O procedimento foi considerado como plenamente aplicável a crianças. Elas formaram conceitos somente após um número significativamente maior de exercícios e buscas se comparadas aos adultos. As crianças de sete e oito anos não apenas aprenderam corretamente a escolher figuras, mas também começaram a apresentar dois atributos essenciais formando um conceito para justificar sua escolha, ao passo que as crianças mais jovens ainda não conseguiam providenciar uma justificativa adequada para o que fizeram. Elas conti- 
nuaram, até no estágio de diferenciação primária, a dar explicações adequadas somente para o primeiro estágio (Stufe der Grundeigenschaft), i.e., apontariam um atributo específico das figuras, por exemplo, peso.

A natureza sistemática das ações e o uso de inferências e conclusões estavam em um nível muito mais baixo nas crianças que nos adultos, como era de se esperar. Ach observou diferenças qualitativas entre os quatro sujeitos a esse respeito; em acréscimo a uma total ausência de forma definida de comportamento, as crianças eram incapazes de terminá-la, ou usá-la racionalmente.

$\mathrm{O}$ método de Ach recebeu posteriormente um uso muito mais abrangente por parte de Rimat e Bacher, entretanto, com certas modificações. ${ }^{(16)}$

Rimat usou o método de Ach para estudar o talento intelectual (odarennost). Em sua perspectiva, o intelecto (intellekt, odarennost) não podia ser reduzido a puro discernimento passivo (Einsicht) ou relações objetivas com o mundo ao redor; um fator não menos importante para caracterizar o talento intelectual foi o fator voluntário, isto é, a força de determinar tendências. Este fator é importante primeiro e acima de tudo porque servirá a diferentes fins pessoais. $\mathrm{O}$ caráter e nível de talento intelectual são expressos mais distintamente no processo de criar e utilizar os diferentes meios necessários para resolver problemas e atingir objetivos vitais. Por exemplo, em testes e experimentos nós encontramos problemas tais como delinear uma conclusão a partir de duas premissas. Mas a vida talvez nunca nos confronte com premissas de modo tão aberto e primitivo, não nos requer delinear conclusões a partir delas. Por isso, até em testes de talento intelectual, uma criança não deve ser diretamente requisitada a efetuar operações psicológicas específicas: deve-se lhe dar tarefas para as quais tais operações psicológicas servem como meio de acesso. O problema é então determinar se a criança é capaz de realizar essas operações psicológicas e usá-las como meios de resolução de problemas. De acordo com Rimat, é errado, e, sobretudo, essencialmente fútil, tentar estudar funções específicas em isolamento e combinar os resultados de discretos testes analíticos para obter um quadro geral do talento intelectual do sujeito. Tais mosaicos põem de lado a unidade: die Einheit der Leistung. Quando somos requisitados a realizar algo em algumas situações de vida, sempre não só ativamos algumas funções mentais isoladas, mas usamos cada caminho e meios adequados a realizar nosso fim, e a falha de uma função pode ser compensada por uma maior utilização de outras funções.

Já que, de acordo com Rimat, talento intelectual é primariamente uma capacidade de usar os próprios processos intelectuais como meio de atingir diferentes fins, o valor sintomático de um teste para medi-lo será maior quanto mais ricas e diversificadas as operações psicológicas que devem ser chamadas para fazer o teste. É somente esta propriedade que distingue o método de busca de Ach. E mais, na maioria dos testes de talento intelectual existentes, é impossível eliminar o significado do conhecimento adquirido na escola e a influência do ambiente. Frequentemente, a performance nos testes depende de reprodução, não de novas criações. Assim, por exemplo, testes de definição de conceitos dependem amplamente do conhecimento escolar, não do talento intelectual. Uma precondi- 
ção para o emprego dos testes de definição de conceitos, tanto quanto de talento intelectual, é que todas as crianças deveriam ter tido a mesma experiência, o que acontece muito raramente. Diferenças na performance, em muitos testes, dependem também das diferenças no grau de domínio da língua. De acordo com Rimat, o método de Ach não tem nenhuma dessas falhas quando usado como teste: dá-se uma tarefa para a criança, e ela é forçada a empregar uma variedade de meios e técnicas para realizá-la. O resultado final dependerá amplamente, então, da extensão em que o comportamento da criança é determinado pela tarefa, se ele vincula as ações da criança em um único processo integral. $\mathrm{O}$ método de Ach nos permite determinar se uma criança é capaz de usar suas próprias operações psicológicas de abstração, formação de conceitos, julgamento e inferência para resolver um problema, vinculando todas essas operações em uma única sequência dirigida ao fim contemplado. Diferenças no conhecimento escolar e na riqueza da experiência das crianças não podem refletir-se na solução da tarefa porque o único aspecto da experiência relevante para resolver o teste de Ach é aquele criado durante os próprios experimentos. Então, como o próprio Ach apontou, estamos aptos em tal caso para reforçar a exigência de testes paralelos arranjados por Karstädt,, ${ }^{(17)}$ porque permite as mais variadas modificações do teste em termos de selecionar objetos, variar as palavras-teste, variar as relações entre os objetos e a série de palavras (com novas combinações dos atributos em conceitos experimentais, por exemplo: substituindo forma + tamanho + peso por forma + tamanho, cor + forma por cor + peso etc.). Isso também permite amplas possibilidades para introduzir diferentes gradações de dificuldade nas tarefas. Por exemplo, o número de atributos que compõem os conceitos pode ser aumentado, ou a ordem normal e modificada pode ser eliminada do período de instrução, de modo que as sessões práticas usem exclusivamente figuras arranjadas em ordem aleatória. Isso, é claro, faz o trabalho consideravelmente mais difícil desde que o sujeito não seja mais capaz de obter auxílio da percepção complexa, o que facilita a formação de conceitos.

Finalmente, há uma vantagem adicional em usar o Suchmethode como um teste: nós obtemos uma indicação de talento intelectual não só teórico como prático. Nos períodos de busca (Suchperiode), a resolução de problemas requer uma certa atividade prática, que pode ter lugar dos modos mais variados. Por outro lado, os processos de abstração e formação de conceitos subjacentes a esta atividade prática, e então a justificativa das crianças para suas ações, suas respostas a questões sobre o que permanecia e para questões durante o período de teste (Prüfungsperiode), caracterizam o talento teórico (teoretitcheskuio odarennost).

À luz dessas considerações, Rimat fez trabalhos de investigação necessários para transformar o método de busca (Suchmethode) em um sistema de testes. Ele criou um número de delineamentos experimentais nos quais ele variou, dos mais diversos modos, tanto a natureza dos problemas quanto as condições de sua apresentação e testou o valor prático de cada variante. Depois de descobrir que, para as crianças entre as idades de dez e 11 anos, os experimentos feitos com um simples método de Ach foram fáceis demais e não produziram meios de distinguir as crianças intelectualmente talentosas dentre aquelas de inteligência mediana, Rimat tornou mais difícil a solução do problema: os testes começaram imedia- 
tamente com 12 figuras em vez de seis, e o treinamento foi feito em uma ordem confusa; a ordem normal e alterada foi totalmente descartada. Então, para obter uma avaliação uniforme e graduar a solução de todos os testes, Rimat introduziu algumas mudanças substanciais na fase de busca. Por exemplo, o experimentador deu à criança o problema de pegar figuras com a inscrição "gazun". A criança o faria. Entretanto, antes de indicar a próxima tarefa, o experimentador retornou as figuras removidas, de modo que, em suas novas buscas, a criança tivesse que trabalhar com o mesmo número de figuras, tal como antes.

Então, para facilitar o processamento dos resultados, o experimentador avaliou não as soluções da tarefa como um todo, como fez Ach, mas a remoção de cada figura individual: se o sujeito, erroneamente, removesse alguma figura, o experimentador imediatamente chamava atenção para o erro. Isso permitiu a Rimat distinguir cinco grupos com base no desempenho na tarefa: primeiro grupo - tarefas realizadas corretamente pelos sujeitos sem qualquer ajuda; segundo grupo - pequena ajuda (por exemplo, primeiro, nem todas as figuras estavam arranjadas, era necessário lembrar, etc.); terceiro grupo - a tarefa foi realizada com um erro; quarto grupo - a tarefa foi realizada com vários erros; e o quinto grupo - realização malsucedida da tarefa. Ao substituir as tarefas desses grupos por números, Rimat obteve uma série numérica caracterizando o processo de variação no nível de performance de resolução de problemas, começando com o primeiro e terminando com o último.

Quanto às razões que as crianças atribuíram às suas ações, Rimat apenas comprovou em qual tarefa uma criança começaria a incluir os dois atributos que caracterizavam o conteúdo dos conceitos experimentais nas razões utilizadas para explicar a ação, ou seja, em que ponto era possível afirmar com absoluta certeza que se realizava a formação de conceitos. Uma comparação desses dados com os de solução de problemas é interessante sob o ponto de vista dos relacionamentos entre o talento intelectual teórico e prático. Rimat ranqueou as crianças com base no número médio de erros realizados em uma tarefa, isto é, com base na relação do número total de figuras erroneamente removidas com o número total de tarefas. Rimat descartou totalmente o período de teste tendo em vista as dificuldades de descrevê-lo quantitativamente.

Por outro lado, exercícios foram introduzidos antes dos experimentos com cada criança, já que a comparabilidade dos resultados dos testes ameaçava-se pela influência das diferenças na velocidade em que as crianças acostumavam-se aos experimentos, quando elas pegavam as figuras e liam o escrito sem entender porque isso era feito. Esse risco era eliminado se, antes do início dos experimentos, a criança atravessasse uma série de testes preliminares, isto é, um número de exercícios práticos e sessões de resolução de problemas com as mesmas figuras, mas com outras palavras e conceitos experimentais.

Se, por exemplo, uma criança tivesse as palavras "vushir", "gak", "zubi" e "dipu" incluídos nos principais experimentos e atributos de cor e forma fossem incluídos no conteúdo dos conceitos que elas designavam, nos exercícios preliminares a criança encontraria "gazun", "ras", "taro" e "fal" e também outras 
combinações de atributos constituindo o conteúdo dos conceitos, isto é, peso e tamanho. Em experimentos especiais, Rimat também mostrou que testes preliminares possibilitaram comparar resultados obtidos de crianças com o método de busca pela primeira vez e crianças que tinham trabalhado com ele antes.

Descobriu-se que, durante os experimentos preliminares, crianças familiarizadas com o método de busca tinham melhores resultados; mas nos principais experimentos, essa desvantagem desapareceu e o principal fator determinante da performance era o nível de talento intelectual da criança.

Como o teste individual de Rimat requer três dias de trabalho (uma hora e meia cada) com cada criança, é muito difícil utilizá-lo para estudar grupos de pacientes. Então, Rimat também concebeu um teste ajustado. Em um teste feito com muitas crianças, Rimat tinha de descartar o período de busca, que ele substituiu por um período de experimentação que, no teste individual, não tinha qualquer função. Isso era feito do seguinte modo: as crianças sentavam-se em modo específico, e figuras individuais com notas anexadas lhes eram dadas. Cada criança deveria ler a inscrição para si própria, olhar atentamente a figura e então passá-la à sua vizinha, e receberia uma nova figura de seu outro vizinho. As figuras eram apresentadas em ordem aleatória. Depois de uma série de repetições, cujo número dependia da idade da criança e natureza do problema, o período de aprendizagem terminava e o de exame começava. Cada criança recebia uma folha de papel e escrevia nela suas respostas para questões escritas no quadro-negro: "Como você reconhece todas as figuras em que a palavra 'gazun' ou 'ras' está escrita?" etc. Então, seguiam-se mais exercícios: os erros dos sujeitos ao responder às questões, sua falta de confiança e até sua inabilidade para fazê-lo levavam, nos novos exercícios, a uma fundamental reorganização da atenção, que era agora dirigida à conexão entre palavras e objetos. Assim, a função do período de busca, o qual era completamente abandonado, era assumido pelas questões no período de teste. Por meio do teste, que durou três dias (uma hora por dia), seis grupos de conceitos com quatro conceitos em cada um foram desenvolvidos. Os primeiros experimentos preliminares e os dois grupos de conceitos formados naquele dia (peso + tamanho, tamanho + forma) não eram levados em consideração na avaliação e determinação da classificação da criança. As respostas dos sujeitos para as questões dividiram-se em cinco grupos. O primeiro, continha crianças com respostas totalmente corretas, às quais se atribuía quatro pontos; o terceiro grupo deu respostas nas quais somente um atributo correto na composição do conceito era indicada, recebendo dois pontos. O quinto grupo dava respostas completamente erradas ou nenhuma: zero pontos. A classificação do sujeito era estabelecida pela somatória dos pontos.

$\mathrm{Na}$ realização desse teste em massa, com muitos grupos de crianças escolares, entre as idades de 11 e 14 anos, Rimat encontrou que o limite inferior de aplicabilidade do teste eram os 12 anos. Depois dos 12, nota-se um avanço considerável na capacidade infantil para formação independente de novos conceitos. Mas a formação de conceitos e pensamento livre de ingredientes sensoriais constituíram demandas que, via de regra, excediam a capacidade de crianças de idade inferior aos 12 anos. Essa foi a conclusão básica de Rimat. 


\section{O MÉTOdO FUNCIONAL DE ESTIMULAÇÃO DUPLA E O ESTUDO DA FORMAÇÃO DE CONCEITOS EM CRIANÇAS}

Agora vamos caracterizar o último estágio no desenvolvimento do método para estudo experimental da formação de conceitos em crianças, aquele em que o método de dupla estimulação adquiriu um novo uso sob a influência da ideia de Vigotski sobre o desenvolvimento de formas superiores de comportamento. Aveling, um psicólogo da era de ascensão da Escola de Würzburg, usou a dupla estimulação não como um método para criar as condições principais do processo de formação dos conceitos de modo a analisá-las, mas como meios técnicos para descrição fenomenológica da vivência do sentido de conceitos plenamente formados. Para psicólogos da escola de Determinationspsychologie, isto é, Ach, Bacher e Rimat, ${ }^{(18)}$ a dupla estimulação desempenha o papel de um ambiente fora do qual é impossível estudar o processo de formação de conceitos. Mas deve ser dito que o problema da dupla estimulação, o problema das formas de comportamento e pensamento com respeito ao qual estímulos externos ficam em duas séries, cada qual com significado funcional diferente, é um problema que os proponentes da Determinationspsychologie ainda não propuseram. Ach compreendeu que, para a formação de conceitos, era necessário ter um número de objetos sob cuja influência os conceitos poderiam formar-se, e um número de palavras para sua formação; mas a atenção do autor não estava centrada na questão do papel específico de cada componente nem, em particular, com a questão do papel fundamental da série verbal. De acordo com a ideia básica da Determinationspsychologie, Ach pensou ser importante mostrar que, em formação de conceito e outros processos de pensamento, estamos lidando com fenômenos que não são tão regulados pelas leis de associação e reprodução de ideias como por "tendências determinantes". Como o próprio Ach apontou, a característica fundamental desse conceito é "regulação de processos mentais de acordo com o sentido (significado) da elaboração de uma finalidade (Zielvorstellung)".

Essas influências especiais, que são dirigidas para a Bezugvorstellung e derivam da elaboração de uma finalidade, determinam o curso dos processos mentais de acordo com a sua imagem; Ach, portanto, denominou-as "tendências determinantes derivadas da percepção de uma finalidade". Um número de características específicas do método de Ach para estudar conceitos é derivado de sua proposição teórica (que não podemos nos encarregar de criticar aqui). A tarefa principal é mostrar que a presença de uma série de objetos e palavras e a acumulação mecânica de associações entre elas é insuficiente para a formação de um conceito. As precondições para a formação de conceitos são apresentadas apenas quando o sujeito elabora uma finalidade, uma tarefa. Sob a influência de uma tarefa e das tendências determinantes dela derivadas, processos mentais passam por uma mudança abrupta.

Tem lugar uma reordenação de todo o plano da consciência: o que tinha antes sido figura agora se torna fundo, e vice-versa. A atenção, que tinha sido previamente centrada na correção do arranjo de objetos, agora se dirige para a conexão entre signos e objetos: alguns arranjos são substituídos por outros, e os 
signos começam a ser usados como meios de orientação na série de objetos. Uma ordem específica de operações psicológicas completamente repetitivas, as operações de arranjar os objetos, etc., ocorre. Mas todos esses processos vinculam-se a um simples todo orgânico totalmente dirigido para a resolução do problema.

É somente se a tarefa está apta a se consolidar com força suficiente, se as influências determinantes que vem dela são suficientemente poderosas para orientar as operações psicológicas em uma nova direção e utilizá-las como meios para realização da tarefa, que a formação de conceitos é possível. Uma ideia do nível de talento intelectual de uma criança pode ser colhida de como o processo de formação de conceitos tem lugar. Isso aponta para certas características específicas do método de Ach. Os experimentos começam com uma associação mecânica de objetos individuais com signos individuais. $O$ sujeito não sabe porque está fazendo isso, ele não tem uma "tarefa". O agrupamento de figuras, a partir de sua simetria, distrai sua atenção das conexões condicionais formadas entre os objetos e os signos verbais, levando à formação de novas conexões, conexões entre os próprios objetos. Como resultado, o mecanismo de associação (até quando o primeiro período de exercício é deliberadamente prolongado para várias dúzias de repetições) torna-se impotente: um conceito não é formado. Embora tenha uma tarefa, o sujeito é incapaz de resolvê-la. Entretanto, ocorre um ponto de inflexão decisivo: apareceram uma tarefa e a elaboração de uma finalidade; todos os processos são gradualmente reordenados, o mecanismo de associação adquire novo uso e, depois de uma ou várias tentativas, a tarefa de selecionar um grupo de figuras é resolvida com base em um conceito formado com o auxílio de palavras. Eis o sentido do método de Ach.

Nós nos aproximamos do processo de formação de conceitos a partir de outro ângulo; portanto, uma crítica e objetiva interpretação psicológica dos resultados de Ach são totalmente supérfluos aqui. Estamos interessados não em determinar o papel da tarefa, mas no especial significado funcional dos signos verbais que, no caso particular, organizam as reações do sujeito que são dirigidas tanto para os estímulos objetivos quanto para o material. Em nosso laboratório, nós denominamos de "estímulos verbais" (riétchvie stimuli) os que desempenham esse papel de estímulos "instrumentais", para referir-se ao seu uso no comportamento do sujeito. A pedido do laboratório, fiz uma tentativa de desenvolver um novo método no qual a principal atenção deve se dirigir para o papel das palavras na formação de conceitos em crianças.

No verão e outono de 1927, conduzi uma série de estudos experimentais utilizando o método de Ach e envolvendo dez crianças normais e cinco mentalmente retardadas entre as idades de seis e 17 anos. Focarei aqui apenas no aspecto metodológico e nos resultados deste estudo. Nós descobrimos que as peculiaridades que se justificavam sob as condições de Ach, em nosso caso, não eram só supérfluas como diretamente prejudiciais. A principal falha no procedimento era que as operações psicológicas em que estávamos interessados não eram suficientemente trazidas à superfície, não eram externamente manifestas. Durante o período de exercício, o comportamento da criança parecia, externamente, confinado à estrutura de uma operação estereotipada: pegar as figuras em 
uma ordem específica e ler nela as inscrições. Esse comportamento externo, monótono, ocultava os ativos processos internos de resposta dos sujeitos à estimulação dupla. Embora os processos internos estivessem em um estado de contínuo desenvolvimento durante o período de exercício durante os cinco a dez dias dos experimentos, isso não era externamente expresso. Portanto, a descrição de Ach dos estágios atravessados pelo processo de formação dos conceitos é baseada principalmente na auto-observação de seus sujeitos adultos, que, obviamente, não se aplica a um procedimento psicológico objetivo. O período em que o sujeito passa pela dupla estimulação é o de exercício. No decurso dela, era muito importante exteriorizar a livre reação de modo a avaliar o papel genético dos estímulos verbal e objetivo. O procedimento de Ach impõe sobre o sujeito (nos interesses de resolver o problema: associação e tendência determinante) uma reação específica, estereotipada, cujo valor sintomático equivale a zero. A dinâmica de desenvolvimento de um conceito experimental em uma criança e os estágios que ela atravessa podem ser esclarecidas somente pela observação durante o período de busca - sem mencionar o fato de que certos estágios intermediários estão além do alcance do investigador, e que a natureza da resposta à estimulação dupla, isto é, a natureza do uso da linguagem pela criança, está totalmente além disso. A falha fundamental do método de Ach do ponto de vista dos nossos objetivos foi o modo como ele organizou a série de objetos. Estamos lidando com um micromundo artificial e simetricamente construído que nos permite descobrir, de forma bastante eficiente, fenômenos que são muito importantes do ponto de vista da Determinationspsychologie, isto é, a sucessão de complexos sob a influência de tendências determinantes, a emergência de um certo número de princípios de ordenação (Ordnungsprinzipien), o uso de interferências, contagem (Hilfskriterien). Todos esses fenômenos são especialmente organizados pelo plano experimental de Ach de mostrar que não apenas o processo de formação de conceitos, mas também o uso de conceitos completamente formados estão sob a influência da preparação de conceitos das quais resulta um arranjo de técnicas auxiliares para economizar esforço. Por contraste, em processos naturais de formação de conceitos, objetos nunca são agrupados em um sistema simétrico tão harmonioso. Entretanto, a falha do procedimento não é simplesmente sua artificialidade, mas o fato de que essa artificialidade contribui para obscurecer a interação que tem lugar entre as reações a estímulos verbais e a estímulos-objeto, com as quais nossos experimentos muito se ocupam. Para determinar a contribuição feita por palavras para a reação de uma criança ao mundo objetivo é mais adequado apresentar esse mundo objetivo como uma diversidade variada, não organizada, que possa ser dominada somente pelo uso de palavras. Mas a relação entre as séries de objetos e palavras deveria ser tal que qualquer reação da criança tipificasse a extensão e a originalidade desse uso. Com base nessas considerações, um procedimento foi desenvolvido sob a liderança de Vigotski, cujos principais fundamentos devo agora apresentar para conclusão desse ensaio. ${ }^{(19)}$

Em um tabuleiro de jogo dividido em campos, cerca de 20-30 figuras de madeira similares às de um jogo de damas são dispostas em cada campo. Essas figuras diferenciam-se por: (1) cor (amarelo, vermelho, verde, preto, branco), (2) 
forma (triângulo, pirâmide, retângulo, paralelepípedo, cilindro), (3) altura (baixo e alto), (4) dimensões planas (pequeno e grande). Uma palavra-teste é escrita no fundo de cada figura. Há quatro diferentes palavras-teste: "bat", escrita em todas as figuras pequenas e baixas, a despeito de sua cor e forma; "dek", pequena e alta; "rots", grande e baixa; "mup", grande e alta. As figuras são arranjadas em ordem aleatória. $\mathrm{O}$ número de figuras de cada cor, forma e de cada um dos outros atributos varia. $\mathrm{O}$ experimentador vira uma figura - um paralelepípedo vermelho, pequeno e baixo - e pede à criança para ler a palavra "bat" escrita em seu fundo exposto. Então, a figura é colocada em um campo especial do tabuleiro, e o experimentador diz à criança que ela tinha diante de si brinquedos pertencentes a crianças de alguns países estrangeiros. Alguns brinquedos são chamados "bat" na linguagem dessas pessoas, por exemplo, a figura virada para cima; outras têm um nome diferente. Há outros brinquedos no tabuleiro que também se denominam "bat". Se a criança faz uma tentativa depois de pensar cuidadosamente onde, no tabuleiro, estão as outras peças chamadas "bat", pega-as e coloca em um campo especial do tabuleiro; ela recebe o prêmio desse campo. O prêmio pode ser um doce, um lápis etc. Os brinquedos não podem ser virados para se ler o que está escrito. A criança deve trabalhar sem pressa, tão bem quanto possível, de modo a não pegar qualquer brinquedo que tenha outro nome e então deixar em um lugar que deveria ser retirado. Ela ensaia as condições do jogo e remove um grupo de figuras, registrando-se o tempo e a ordem em que a criança remove as figuras. Os mais variados tipos de respostas são observados: reações-teste sem qualquer razão, escolha com base em um arranjo (por exemplo, formar uma coleção), escolhas com base em uma máxima similaridade, com base na similaridade de um atributo etc. $\mathrm{O}$ experimentador pergunta porque a criança pega esses brinquedos e quais deles são chamados "bat" na língua do povo estrangeiro. Então, faz com que a criança vire uma das figuras não removidas e veja que "bat" está escrito nela. "Aqui, olhe, você errou; o prêmio ainda não é seu". Por exemplo, se a criança pega todos os paralelepípedos apesar de sua cor e tamanho com base no fato de o modelo ser um paralelepípedo, o experimentador faz com que ele exponha o círculo pequeno, curto e vermelho "bat", de cor similar ao modelo. A figura virada é colocada com a inscrição para cima, ao lado do modelo. As figuras removidas pela criança retornam ao tabuleiro, e se lhe pede novamente para tentar ganhar o prêmio pegando todos os brinquedos "bat" com base nos dois que ela conhece. Uma criança removerá todas as figuras vermelhas; outra, todos os paralelepípedos e cilindros; uma terceira selecionará uma coleção de figuras de diferentes formas; outras repetirão sua resposta precedente; uma quinta fará uma escolha de figuras completamente arbitrária etc. O jogo continua até que a criança pegue todas as figuras corretamente e dê uma definição correta do conceito "bat". Assim, o princípio básico de nosso procedimento é que se dá a série de objetos de forma completa desde o início do jogo, mas a série verbal é gradualmente aumentada; todos os novos itens dessa série, gradualmente, entram no jogo um por um. Depois de cada mudança na série verbal, isto é, na natureza da dupla estimulação, a criança nos dá sua livre reação, com base na qual podemos avaliar o grau de utilização funcional dos itens na série verbal e as reações psicológicas da criança à série de objetos. 
Fizemos um estudo preliminar do processo de formação de conceitos em adultos usando um método similar, e, no presente, estamos completando um estudo análogo das crianças.

Assim podemos descrever as características básicas do método desenvolvido: há uma coleção de figuras de diferentes formas, cores, alturas e dimensões planares. Diversamente do arranjo de figuras de Ach, essa coleção é um todo variado, não organizado: irregular e assimétrico. Atributos diferentes ocorrem em um número de vezes desigual. A coleção baseia-se em quatro conceitos experimentais associados a palavras-teste, que são escritas no fundo das figuras, invisíveis para a criança. Cada conceito contém dois atributos, por exemplo, altura e dimensões planares. Um conceito envolve todas as figuras grandes e altas; o outro, todas as altas e pequenas, a terceira, todas as baixas e pequenas; e a quarta, todas as grandes e baixas. $\mathrm{O}$ experimento é feito como um jogo. As figuras são arranjadas aleatoriamente em um tabuleiro de jogo, sem padrão. [O experimentador diz à criança que esses] são brinquedos de um país estrangeiro. Um deles é virado para cima, e se lê em voz alta o nome dele no idioma dessas pessoas. De acordo com as regras do jogo, a criança deve remover todos os brinquedos que têm nome igual ao do modelo virado para cima e colocá-los em um campo especial do tabuleiro sem os virar e olhar a inscrição. Em troca, ela obtém, como prêmio, um doce, um lápis ou algo desse tipo. O jogo todo consiste nas tentativas da criança em colocar corretamente todas as figuras com a inscrição igual ao modelo. Depois de cada tentativa, o experimentador vira a nova figura, revelando o erro da criança, que consiste na existência de [ao menos - N. da T.] uma com nome diferente do modelo, ou, entre as figuras não removidas, alguma com o mesmo nome que o modelo - e, portanto, pertencente ao campo. Uma vez que, depois de cada colocação das figuras, a criança tenha descoberto uma nova figura adequada (localizada pelo experimentador), cada tentativa da criança é feita com base em um número maior de modelos.

Assim, o princípio do experimento é que a série de objetos é dada à criança imediatamente, como um todo, mas a série de palavras é dada gradualmente, e a natureza da estimulação dupla varia continuamente. Depois de cada mudança obtemos a livre resposta da criança, que nos permite avaliar as mudanças que tiveram lugar nas operações psicológicas dela como consequência do fato de que a série de objetos, agora, contém um novo elemento da série verbal. Isso nos permite avaliar o grau em que uma criança faz uso das palavras. É claro, a tarefa pode ser realizada corretamente apenas se os conceitos experimentais subjacentes às palavras-teste foram formados. Em um procedimento similar, realizamos um estudo da formação de conceitos em adultos e comprovamos sua produtividade. Agora estamos completando um estudo da formação de conceitos em crianças escolares e começamos a trabalhar com crianças pré-escolares, para quem signos verbais são trocados por signos coloridos arbitrários. Estamos também no processo de desenvolvimento e provas de um novo teste. ${ }^{(20)}$

Uma ilustração da natureza dos dados que pode ser obtida com base neste procedimento pode ser vista no fato de que uma palavra em nossos experimentos passe por três estágios que estão presentes na ontogênese dos conceitos infantis. 
Inicialmente, é um signo individual como seu próprio nome; então, torna-se um signo de família com seu próprio nome associado a uma série de objetos concretos (Pluralbegriff - conceito por complexo); finalmente, começa uma abstração geral. Algumas crianças atravessam todos esses três estágios; outras permanecem no estágio intermediário. Assim, temos um quadro experimental organizado da ontogênese de conceitos e temos a possibilidade de realizar uma pesquisa para análise do papel funcional das palavras em todos os estágios de sua ontogênese.

\section{Notas}

Publicado pela primeira vez como Sakharov, L.S. 1930: O metodakh issledovaniya ponyatii). Psikhologija, 3, 3-32. Segundo a edição em russo que utilizamos (Sakharov, 2006), trata-se de uma comunicação para o Congresso Pedológico ocorrido em Moscou, a 1 de janeiro de 1928. Recebido em 12 de outubro de 1929. A referência do original que utilizamos para comparar a tradução americana com a russa é: Sakharov L.S. On methods for investigating concepts. Cultural-Historical Psychology. 2006 \#2. - P. 32-47. Disponível em: http://psyjournals.ru/en/ kip/2006/n2/Sakharov.shtml.

A tradução ao inglês, feita por Michel Vale, baseou-se em outra publicação: a da Soviet Psychology, 1990, 28,35-66, Julho/Agosto. O artigo baseou-se em uma comunicação apresentada por Sakharov no Congresso Pedológico de Moscou em Janeiro de 1928. Pouco tempo depois - em 10 de Maio de 1928 - Sakharov morreu em circunstâncias desconhecidas. Leonid Solomonovich Sakharov (1900-1928) trabalhou com Vigotski no Instituto Experimental de Psicologia (encabeçado por Kornilov) e rapidamente começou a cooperar com Vigotski. Sua única outra publicação que conhecemos também se referia a métodos (alemães) de investigação da formação de conceitos. Veja-se Sakharov, L. S. 1928: Obrazovanieponjatij u umstvenno-otstalykhdetej (Referat) ("A formação de conceitos em crianças mentalmente retardadas" (uma sinopse). Voprosy Defektologuii, 2, 24-33.

\footnotetext{
${ }^{1}$ Provavelmente, este parágrafo refere-se às seguintes publicações: Binet, A. 1903: L'étude expérimentale de l'intelligence. Paris: Schleicher; Bobertag, O. 1911: Über Intelligenzprufungen (nach der Methode von Binet und Simon). Zeitschrift für angewandte Psycbologie, 5, 105-203; Eng, H. 1914: Abstrakte Begriffe im Sprechen und Denken des Kindes. Zeitschrift für angewandte Psycbologie. Beiheft 8; Gregor, A. 1915: Untersuchungen uber die Entwicklung einfacher logischer Leistungen. . Zeitschrift für angewandte Psycbologie, 10, 339-451.

A referência a Pelman é pouco acurada. Por descrição da família de Sakharov, entre as psicologias que ele admirava na época, figuravam trabalhos de John R. Pelsma, que pediu à filha de quatro anos para definir as palavras conhecidas por ela. Veja-se Pelsma, J.R. 1910: O vocabulário de uma criança e seu desenvolvimento. The Pedagogical Seminary, 17, 328-69. Outra possibilidade é que Sakharov tencionou referir-se ao trabalho de Hans Pohlman. Neste caso, uma fonte plausível é Pohlman, H. 1912: Beitrag zur Psychologiedes Schulkindes. Pädagogische Monographien. Vol. 13 Leipzig: Otto NemnichVerlag. Pohlmann investigou o desenvolvimento da compreensão infantil de significados de palavras.

Roloff, H. P. 1922: Vergleichend-psychologische Untersuchungen überkindlichen Definitionsleistungen. Leipzig: Barth;

Moede, W. 1916: Die Methoden der Begriffsuntersuchung. Zeitschriftfürpädagogische Psychologie und experimentelle Pädagogik, 17, 149-66.

${ }^{2}$ Aparentemente, trata-se de Lindworsky, J. 1916: Das schlussfolgernde Denker //
} 
Experimentelle psychologische Untersuchengen. Freiburg: Herder.

${ }^{3} \mathrm{Na}$ presente comunicação usamos a palavra "conceito" no sentido tradicional que tem na psicologia experimental, a qual herdou a definição desse termo da lógica formal. Um conceito neste sentido (uma ideia geral, o significado de uma palavra), não é um conceito para a lógica dialética; entretanto, está sinteticamente relacionado à última como estágio específico em seu desenvolvimento e estrutura.

${ }^{4}$ Provavelmente, a referência é às seguintes publicações: Grünbaum, A. A. 1908: Über die Abstrakrion der Gleichheit. Archiv für die Gesamte Psychologie, 12, 340-478; Habrich, J. 1914: Über die Entwicklung der Abstraktionsfähigkeit von Schülerinnen. Zeitschrift für angewandte Psychologie, 9, 189-244; Koch, A. 1913: Experimentelle Untersuchungenüber die Abstraktionsfähigkeit von Volkschulkinderen. Zeitschrift für angewandte Psychologie, 7, 33291; Kuenburg, M. von 1920: Über Abstraktionsfähigkeit und die Entstehung von Relationen beim vorschulpflichtigen Kinde. Zeitschrift für angewandte Psychologie, 17, 270-312. Não conseguimos localizar o artigo de Heffler e não sabemos se Heffler é a ortografia correta do nome do autor. De fato, L.S. Sakharov cometeu erros na transliteração dos sobrenomes de pesquisadores (pode ter sido Alois Höfler, por exemplo).

${ }^{5}$ Sakharov provavelmente referiu-se a Eliasberg, W. 1925: Psychologie und Pathologie der Abstraktion. Zeitschrift für angewandte Psychologie. Beiheft 35. Leipzig: Barth.

${ }^{6}$ Provavelmente, o autor refere-se à publicação: Katz, D. 1913: Über gewisse Abstraktionsprozesse bei vorschulpflichtigen Kinder. Wissenschaftliche Beiträge zur Pädagogik und Psychologie, 4. Leipzig: Quelle \& Meyer.

${ }^{7}$ A referência pode ser a Tobie, H. 1926: Die Entwicklung der teilinhaltlichenBeachtung von Farbe und Form imvorschulpflichtigen Alter. Zeitschrift für angewandte Psychologie. Beiheft 38.

${ }^{8}$ São conhecidas algumas publicações de Lindner. Por exemplo, Lindner, G. 1882: Beobachtungen und Bemerkungenüber die Entwicklung der Sprache des Kindes. Kosmos, 6, 321-42;430-41; Lindner, G. 1885: Zum Studium der Kindersprache. Kosmos, 9, 161-73; 241-59; ou Lindner, G. 1906: Neuere Forschungen und Anschauungenüber über die Sprache des Kindes. Zeitschrift für pädagogische Psychologie, Pathologie, und Hygiene, 7, 337-92. Schriftbilder (alemão) são imagens mentais ou representações de um texto escrito.

${ }^{9}$ Provavelmente, Sakharov escreveu incorretamente o nome de família, referindo-se a Beckinann em vez de Beckmann. Beckmann, H. 1923: Die Entwicklung der Zahlleistung bei 2-6 jährigen Kindern. Zeitschrift für angewandte Psychologie, 22, 1-72 ; e a Descoeudres, A. 1921: Le développement de 1'enfant de deux à sept ans. Neuchatel: Delachaux et Niestlé.

${ }^{10}$ Provavelmente, refere-se ao seguinte trabalho: de Aveling, F. 1912: On the Consciousness of the Universal and the Individual. London: Macmillan. p. 75

${ }^{11}$ Sakharov podia conhecer muitas publicações de Ribot. No caso em questão, talvez se apoiasse em Ribot 1891: Enquête sur les idees generales na Revue Philosophique, 32,376-88; e Ribot, Th 1897: L'evollution des idées générales. Paris: Alcan.

${ }^{12}$ Ach, N. 1921: Über die Begriffsbildung. Eine experimmentelle Untersuchung. Bamberg: C. C. Büchners Verlag.

${ }^{13}$ Köhler, W. 1921: Intelligenzprüfungen an Menschenaffen. Berlin: Julius Springer.

Em russo, era conhecido o livro de W. Köhler: "Pesquisa sobre o intelecto de macacos antropóides". M.: Editora da Academia Comunista, 1930. A tradução do livro do alemão ao russo foi de L.V. Zankov e I.M. Soloviev, sob redação geral e introdução de L.S Vigotski.

${ }^{14}$ Ach usou, em acréscimo a esse método, outro método para o estudo de conceitos, o assimchamado Verstandigungsmethode (o método de comunicação), que se baseia no desenvolvimento de um conceito utilizando-se um novo aspecto funcional: uma palavra, que serve como meio de esclarecimento mútuo e comunicação, adquire significado, e se torna o suporte de um conceito [nota de rodapé original].

${ }^{15}$ Uma referência confusa. Está claro que se solicitava às crianças construir sentenças com os conceitos recentemente adquiridos, mas não se sabe quem foi Maselonovsky (se a ortografia estiver correta).

${ }^{16}$ Provavelmente, refere-se a Rimat , F. 1925: Intelligenzuntersuchungen anschliessend an die Ach'se Suchmethode. Untersuchengen zur Psychologie, Philosophie und Pädagogik, 5, 3/4, 1-116 (referências a este livro encontramos na monografia "Pensamento e linguagem", de L.S. Vigotski); e Bacher, G. 1925: Die Ach'she Suchmethode in ihrer Verwendung zur Intelligenzprüfung. Ein Beitrag zur Psychologie des Schwachsinns. Untersuchugen zur Psychologie, Philosophie und Pädagogik, 4, 3/4, 209-289. 
${ }^{17}$ É plausível que a fonte de Sakharov seja: Karstädt, O. 1918: Zur Schaffung von Paralleltests // Zeitschrift fur angewandte Psychologie, 13, 305-53.

${ }^{18}$ Sobre a pesquisa e o método de Bacher, ver: L. S. Sakharov 1928 [Formação de conceitos em crianças mentalmente retardadas], Voprosy defektologuii, $\mathrm{N}^{\circ} .2$.

É interessante que a revista "Voprosi defektologuii" foi criada em 1928! No número 4 daquele ano, publicou o artigo de A.N. Leontiev, "Memória não-mediana de crianças com deficiências e intelecto enfermiço e defectivo (dados iniciais de pesquisa)". O artigo de Sakharov faz referência ao trabalho - Bacher G. Die Ach'she Suchmethode in ihrer verwerdung zur Intelligenzerufung. Ein Beitrag zur Psychologie des Schwachsinus // Untersuchengen zur Psychologie, Philosophie und Padagogik. Herausgeg, von Narziss Ach, 1925. G. Bacher sugeriu calcular o índice específico, que permitisse julgar o grau de desenvolvimento de conceitos da criança - se ela faz conclusões do concreto ao concreto ou se já existem conceitos. Também, na discussão do trabalho qualitativo de avaliação do nível de desenvolvimento intelectual da criança retardada, G. Bacher criticou a escala Binet-Simon, na qual se realiza avaliação quantitativa do intelecto, e se compara a criança com atraso mental à de menor idade. A ideia de Bacher era de que a testagem breve, executada em um único dia, não era adequada à avaliação intelectual das crianças retardadas. Ele mostrou que as peculiaridades da atividade intelectual relacionaram-se à fraqueza de iniciativa e à falta de autocontrole. "As conclusões positivas destes estudos de Bacher apontam na seguinte direção: Ach, de modo especial, mostrou a dependência dos processos intelectuais superiores com relação aos fatores volitivos, em particular, como premissa para que as manifestações do processo de formação dos conceitos, a suficiência da força da "tendência determinante", capacidade de uma criança no curso de um certo período de tempo conhecido dirigir sua percepção para a correlação com a tarefa proposta. Entre elas há apenas aquela capacidade gravemente insuficiente. Portanto, [relaciona-se] longo e insustentável trabalho mental e a realização de processos mentais superiores. Portanto, não pode sair dos limites da experiência concreta, elaborar sua 'formação de conceitos'.” L.S. Sakharov. Ukazannoe isdanie. S.33 .

Provavelmente, Sakharov fala do laboratório onde trabalhou L.S. Vigotski em 1924 no Instituto Estatal de Psicologia Experimental (Moscou), àquela época, dirigido por K.N. Kornílov. L.S. Sakharov foi colaborador externo. Veja-se a coletânea: Problemas de Psicologia Moderna: artigos dos colaboradores do Instituto Estatal de Psicologia Experimental de Moscou, sob edição de K.N. Kornilov. L.: Gos. Isdva, 1926. A seção "Estrutura do Instituto" mostra L.S. Sakharov como colaborador externo da seção de psicologia geral e experimental - sendo Kornilov o chefe da seção. L.S. Vigotski foi colaborador científico por dois anos nessa seção, quando redigiu o trabalho: "Pesquisa das reações dominantes". Além de Vigotski, trabalharam Sakharov, L.V. Zankov e I.M. Soloviev. Mas esses dados são de 1926; não se sabe sobre 1928.

${ }^{19}$ No presente artigo, considera-se somente a variante desenvolvimento "estudos de formação de conceitos", trabalhada com respeito à pesquisa com crianças. O autor apresenta em outra oportunidade a justificativa teórica e metodológica para esse procedimento quanto à variante básica do estudo da formação de conceitos em adultos. Infelizmente, não foi possível encontrar essa publicação na qual L.S. Sakharov apresenta os dados obtidos. No "Guia da literatura publicada pelo Instituto de Psicologia em 50 anos (de 1917 a 1967)” (Moscou, 1967), não há menção à publicação de L.S. Sakharov para além da publicação de 1928 no periódico "Problemas de defectologia”. Também não há menção a outras publicações de Sakharov na edição de referência de "Jurnalnaia Letopis". (Gosudarstvennaia Tsentralnaia Knijnaia da URSS, entre 1927 e 1930). Provavelmente, os resultados da pesquisa não foram publicados.

${ }^{20}$ A maior parte do estudo começou e foi realizado por L. S. Sakharov no Instituto de Psicologia Experimental de Moscou, sendo completado por L. S. Vigotski, Yu. V. Korelova e E. I. Pashkovskaya, e preparado para a impressão na forma de uma monografia. Os resultados principais dessa investigação foram apresentados por Vigotski no Primeiro Congresso para o Estudo do Comportamento Humano, em Leningrado, Janeiro de 1930 (Seção sobre Psicologia, Reflexologia e Fisiologia do Sistema Nervoso). Ver Vigotski, L. S., 1930: Eksperimental'noe issledovanie vyssikh processov povedeija. 